\title{
Psychosocial Health of Disease-Free Breast Cancer Survivors Compared with Matched Non-cancer Controls
}

\author{
Boyoung Park, MD, $\mathrm{PhD}^{1,2}$ \\ Moo Hyun Lee, MD, MS 34 \\ Sun-Young Kong, MD, PhD,6 \\ Eun Sook Lee, MD, PhD23,5
}

\begin{abstract}
${ }^{1}$ Department of Medicine, Hanyang University College of Medicine, Seoul, ${ }^{2}$ National Cancer Center Graduate School of Cancer Science and Policy, Goyang, ${ }^{3}$ Center for Breast Cancer, Hospital, National Cancer Center, Goyang, ${ }^{4}$ Department of Surgery, Keimyung University School of Medicine, Daegu, ${ }^{5}$ Research Institute, National Cancer Center, Goyang, ${ }^{6}$ Department of Laboratory Medicine, Hospital, National Cancer Center, Goyang, Korea
\end{abstract}

\begin{abstract}
Purpose
The present study investigated the psychosocial health of disease-free breast cancer survivors who receive health examinations compared to matched non-cancer controls in a community setting.
\end{abstract}

\section{Materials and Methods}

We used baseline data from the Health Examinee cohort, which is composed of subjects participating in health. The disease-free breast cancer survivors were defined as those who were $\geq 2$ years from initial diagnosis of breast cancer who had completed treatment. Females without a history of cancer were randomly selected at 1:4 ratio by 5-year age groups, education, and household income as a comparison group. We analyzed results from the Psychosocial Well-being Index-Short Form (PWI-SF) as a psychosocial health measurement.

\section{Results}

A total of 347 survivors of breast cancer and 1,388 matched controls were included. Total scores on the PWI-SF were lower in breast cancer survivors than matched non-cancer controls ( $p=0.006$ ), suggesting a lower level of psychosocial stress in breast cancer survivors. In comparison to the control group, prevalence of drinking, smoking and obesity were lower, while exercising for $\geq 150 \mathrm{~min} /$ wk was higher in breast cancer survivors $(p<0.05)$. These findings suggest that breast cancer survivors have better health behaviors than their noncancer controls. After adjusting for other sociodemographic variables, breast cancer survivors were $36 \%$ less likely to be included in the stress group (odds ratio, 0.64; 95\% confidence interval, 0.42 to 0.98 ).

\section{Conclusion}

The disease-free breast cancer survivors resuming daily life demonstrated better psychosocial health status compared to matched non-cancer controls. ax: 82-31-920-1511

E-mail: eslee@ncc.re.kr

Received December 10, 2017

Accepted April 3, 2018

Published Online April 5, 2018

*Boyoung Park and Moo Hyun Lee contributed equally to this work.

\section{Key words}

Breast cancer survivors, Psychosocial health,

Psychosocial Well-being Index-Short Form, Community setting

\section{Introduction}

Breast cancer is the second-most common cancer, followed by thyroid cancer, among Korean women, and although the mortality from this disease is quite low, it is the most prevalent cancer among women globally [1-3]. The number of long-term survivors is rapidly growing due to the increasing rates of detection and incidence as well as improved survival
$[4,5]$. The increasing number of breast cancer survivors urges the examination of the long-term effects of breast cancer. Survivors of breast cancer are at risk of not only recurrence and secondary cancer but also non-cancerous medical problems, such as cardiovascular diseases, endocrine diseases, poor quality of life, and functional decline related to cancer treatment [6-8].

The long-term effects of breast cancer and its treatment have been shown to have both positive and negative effects 
on survivors' quality of life (QOL) [9]. Additionally, QOL in terms of physical functioning and psychosocial health outcomes vary across the breast cancer continuum including diagnosis at different stages of breast cancer, disease-free survivorship beyond the first course of primary treatment, longterm disease-free survivorship, and first recurrence of breast cancer [10]. Poor psychosocial health is attributed to worries about recurrence [11,12]. Long-term breast cancer survivors report a higher prevalence of mild to moderate depressive symptoms than healthy controls, with prevalence rates of at least 15\% 5 years after their diagnosis versus $4.5 \%$ to $9.3 \%$ among women in healthy community samples [12-15]. While several studies have investigated various aspect of psychosocial health including QOL, depression, subjective health status and psychosocial distress in short-term and long-term breast cancer survivors, most studies have focused on the psychosocial health related to time since diagnosis, treatment status, or recurrence. Although the spectrum of breast cancer includes diagnosis, primary treatment, genetic risk and its psychological management, recurrence, completing treatment and re-entry to normal living, survivorship, and palliation for advanced cancer [10], little research has investigated breast cancer survivors who have completed treatment and resumed normal daily activities. Thus, research focusing on breast cancer survivors with complete recovery in a community-based setting may offer valuable and novel insight.

The Health Examinee (HEXA) cohort recruits participants from health examination centers located nationwide who get regular health checkups, and it includes healthy individuals as well as individuals with various chronic diseases including cancer. By using data from HEXA cohort baseline examination and survey as a cross-sectional approach, the present study assessed and compared the psychosocial health of disease-free breast cancer survivors who had completed treatment and resumed daily life to a matched non-cancer controls.

\section{Materials and Methods}

\section{Data source and study population}

The HEXA cohort, which is a part of the Korea Genome Epidemiology Study (KoGES) was used. The HEXA cohort is a large-scale cohort study established between 2004 and 2014 by the Korea Centers for Disease Control and Prevention and collects clinical and epidemiological data using standardized questionnaire as well as bio-specimens of participants after informed consent is given. The HEXA cohort recruited examinees aged 40-70 from health examination cen- ters located in 14 urban areas during 2004-2013. Details of the KoGES and HEXA cohort protocol including questionnaire development are described in other literature [16].

Baseline questionnaire regarding past medical history included whether they had been diagnosed with cancer by a physician, types of cancer diagnosed, age at diagnosis, and current treatment status (complete treatment, under treatment, left untreated, or never-treated). With questionnaire regarding past medical history, we classified female participants into those with history of breast cancer (prevalent breast cancer cases) and those without history of any types of cancer. A total of 859 female participants reported that physician had diagnosed them with breast cancer at the baseline survey, and the mean value of time since diagnosis was $6.0 \pm 5.5$ years (range, 0 to 41 years). We defined breast cancer survivors as those who reported that they were $\geq 2$ years from the initial diagnosis of breast cancer and had completed treatment without recurrence at the time of baseline survey of HEXA cohort. We excluded subjects who were $<20$-years of age at first diagnosis and those with missing variables in the Psychosocial Well-being Index-Short Form (PWI-SF) at the baseline survey [17]. Disease-free breast cancer survivors were matched with non-cancer controls at 1:4 ratio by frequency matching. Female participants without a history of any cancer and who completed the PWI-SF at the time of baseline survey of HEXA cohort were randomly selected according to 5-year age groups, educational attainment level (less than high school, high school, and college or more), and household income level $(<\$ 3,000 / \mathrm{mo}$ and $\geq \$ 3,000 / \mathrm{mo})$ as a comparison group (referred to as matched non-cancer controls). Ultimately, 347 survivors of breast cancer and 1,388 matched participants without cancer histories were selected for analysis (Fig. 1).

\section{Psychosocial health}

The PWI-SF, the shortened form of PWI corrected for General Health Questionnaire-60 made and validated by Chang [17], was applied to measure the level of psychosocial stress. The PWI-SF has been administered to access psychosocial stress level in various studies such as the largest population based cohort study [16], a stroke cohort [18], automobile workers stress study [19], and firefighters' stress study [20]. The PWI-SF, with a total score range from 0 to 54 , consists of 18 items in four scales on a 4-point Likert scale: social performance and self-confidence of 8 items, depression of three items, sleeping disturbance and anxiety of three items, and general well-being and vitality of four items. The subject is asked to assess changes in his/her mood, feelings and behaviors in the period of recent several weeks and is classified the healthy group, which consisted those with score $\leq 8$, the latent stress group (score 9-26), and the stress group 


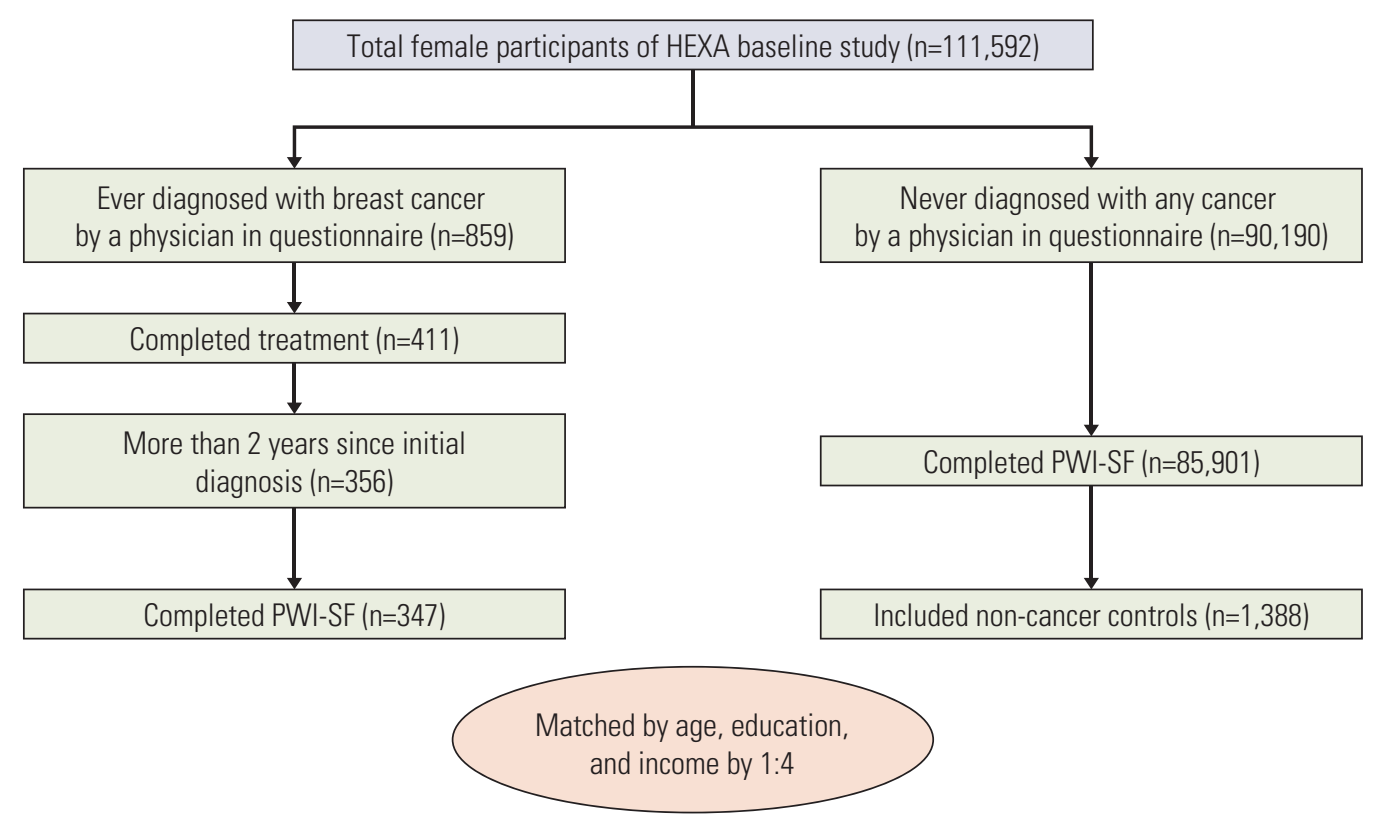

Fig. 1. Study profile of disease-free breast cancer survivors and matched non-cancer controls. HEXA, the Health Examinee cohort; PWI-SF, Psychosocial Well-being Index-Short Form.

which contained those with scores $\geq 27$ [18]. Breast cancer survivors and matched non-cancer controls were classified into two groups: the healthy group, which consisted those with score $\leq 26$, and the stress group which contained those with scores $\geq 27$.

\section{Definition of variables}

Other sociodemographic characteristics were defined as follows: marital status was categorized into currently married and unmarried, which included never married, separated, divorce, and bereavement. Drinking and smoking were categorized by past/current (presented as "ever drinker/ smoker") or never. Exercise behavior was classified according to the American Cancer Society Physical Activity Guidelines for Cancer Survivors, which recommends $\geq 150$ minutes of exercise per week [21]. Post-menopausal women were defined as those who had not experienced menstruation for the past 12 months. Body mass index (BMI) was categorized as $<25$ or $\geq 25 \mathrm{~kg} / \mathrm{m}^{2}$. Current job status was classified as unemployed when a participant reported being unemployed or a housewife and employed. Subjective health status was measured as very healthy, healthy, normal, unhealthy, or very unhealthy and was classified into "very healthy, healthy" and "normal-very unhealthy."

\section{Statistical analysis}

The sociodemographic characteristics of the female breast cancer survivors and their matched non-cancer controls were compared using a chi-square test for categorical variables and a t test for continuous variables. The mean score of the PWI-SF among breast cancer survivors and matched noncancer controls was compared using a t test according to each socioeconomic characteristic. After adjusting for other sociodemographic characteristics such as marital status, smoking status, drinking status, exercise, menopausal status, BMI, current job status, and subjective health status, a multivariable conditional logistic regression was conducted to investigate whether stress levels were higher in breast cancer survivors than matched non-cancer controls because breast cancer survivors and matched non-cancer controls were matched by age, education, and income level. All statistical analyses were conducted using SAS software ver. 9.1 (SAS, Inc., Cary, NC).

\section{Ethical statement}

The Institutional Review Board of the National Cancer Center approved this study protocol (IRB No. NCC20140098). Informed consents were obtained from all participants. 
Table 1. General characteristics of breast cancer survivors and matched non-cancer controls

\begin{tabular}{|c|c|c|c|}
\hline Variable & $\begin{array}{c}\text { Breast cancer } \\
\text { survivors }(n=347)\end{array}$ & $\begin{array}{l}\text { Matched females } \\
\qquad(n=1,388)\end{array}$ & p-value \\
\hline Age (yr) & $55.8 \pm 7.1$ & $55.5 \pm 7.9$ & 0.358 \\
\hline \multicolumn{4}{|l|}{ Education } \\
\hline Less than high school & $137(39.9)$ & $568(41.2)$ & 0.910 \\
\hline High school & $126(36.7)$ & $497(36.1)$ & \\
\hline College or more & $80(23.3)$ & $313(22.7)$ & \\
\hline \multicolumn{4}{|l|}{ Income (\$/mo) } \\
\hline$<3,000$ & $175(57.6)$ & $699(57.7)$ & 0.961 \\
\hline$\geq 3,000$ & $129(42.4)$ & $512(42.3)$ & \\
\hline \multicolumn{4}{|l|}{ Marital status } \\
\hline Currently unmarried & $52(15.0)$ & $228(16.5)$ & 0.498 \\
\hline Currently married & $295(85.0)$ & $1,155(83.5)$ & \\
\hline \multicolumn{4}{|l|}{ Smoking status } \\
\hline Never & $344(99.4)$ & $1,336(96.5)$ & 0.004 \\
\hline Ever & $2(0.6)$ & $49(3.5)$ & \\
\hline \multicolumn{4}{|l|}{ Drinking status } \\
\hline Never & $278(80.1)$ & $950(68.6)$ & $<0.001$ \\
\hline Ever & $69(19.9)$ & $435(31.4)$ & \\
\hline \multicolumn{4}{|l|}{ Exercise (min/wk) } \\
\hline$<150$ & $189(55.1)$ & $833(62.3)$ & 0.015 \\
\hline$\geq 150$ & $154(44.9)$ & $504(37.7)$ & \\
\hline \multicolumn{4}{|l|}{ Menopausal status } \\
\hline Premenopause & $39(11.2)$ & $425(30.6)$ & $<0.001$ \\
\hline Postmenopause & $308(88.8)$ & $963(69.4)$ & \\
\hline \multicolumn{4}{|l|}{ Body mass index $\left(\mathrm{kg} / \mathrm{m}^{2}\right)$} \\
\hline$<25$ & $162(47.0)$ & $600(43.4)$ & 0.232 \\
\hline$\geq 25$ & $183(53.0)$ & $783(56.6)$ & \\
\hline \multicolumn{4}{|l|}{ Current job status } \\
\hline Unemployed & $230(67.1)$ & $877(65.5)$ & 0.307 \\
\hline Employed & 113 (32.9) & $461(34.4)$ & \\
\hline \multicolumn{4}{|l|}{ Subjective health status } \\
\hline Very healthy, healthy & $101(29.3)$ & $484(34.9)$ & 0.046 \\
\hline Normal-very unhealthy & $244(70.7)$ & $901(65.1)$ & \\
\hline \multicolumn{4}{|l|}{ Stress level } \\
\hline Healthy group & $41(11.8)$ & $140(10.1)$ & 0.057 \\
\hline Latent stress group & $276(79.5)$ & $1,065(76.7)$ & \\
\hline Stress group & $30(8.7)$ & $183(13.2)$ & \\
\hline
\end{tabular}

Values are presented as mean \pm standard deviation or number $(\%)$.

\section{Results}

The demographics of the breast cancer survivors and matched non-cancer controls were compared (Table 1). Age, education and income level which were matched when selecting controls did not differ between the two groups. The proportions of ever drinkers and ever smokers, and proportion of those whose subjective health status was healthy were lower among breast cancer survivors than the matched noncancer controls. Additionally, breast cancer survivors reported significantly high rates of exercising $\geq 150 \mathrm{~min} / \mathrm{wk}$ and postmenopausal status than their matched non-cancer controls $(p<0.05)$. The prevalence of latent stress and stress in breast cancer survivors was $79.5 \%$ and $8.7 \%$ respectively, while the matched non-cancer controls reported $76.7 \%$ and $13.2 \%$, respectively, showing borderline significant differences $(p=0.057)$. 
Table 2. Total score of Psychosocial Wellbeing Index-Short Form between breast cancer survivors and matched non-cancer controls according to sociedemographic characteristics

\begin{tabular}{|c|c|c|c|}
\hline Variable & Breast cancer survivors & Matched females & p-value $e^{a)}$ \\
\hline Total & $15.8 \pm 7.1$ & $17.0 \pm 8.0$ & 0.006 \\
\hline \multicolumn{4}{|l|}{ Education } \\
\hline Less than high school & $16.5 \pm 7.8$ & $18.1 \pm 8.6$ & 0.039 \\
\hline High school & $16.1 \pm 7.0$ & $16.4 \pm 7.7$ & 0.664 \\
\hline College or more & $14.2 \pm 5.9$ & $15.8 \pm 7.2$ & 0.045 \\
\hline \multicolumn{4}{|l|}{ Income (\$/mo) } \\
\hline$<3,000$ & $15.7 \pm 7.5$ & $17.6 \pm 8.2$ & 0.006 \\
\hline$\geq 3,000$ & $15.5 \pm 6.5$ & $15.7 \pm 7.3$ & 0.745 \\
\hline \multicolumn{4}{|l|}{ Marital status } \\
\hline Currently unmarried & $18.2 \pm 8.4$ & $18.3 \pm 8.2$ & 0.918 \\
\hline Currently married & $15.4 \pm 6.8$ & $16.8 \pm 8.0$ & 0.003 \\
\hline \multicolumn{4}{|l|}{ Smoking status } \\
\hline Never & $15.8 \pm 7.2$ & $16.9 \pm 8.0$ & 0.011 \\
\hline Ever & $15.5 \pm 3.5$ & $19.3 \pm 9.8$ & 0.594 \\
\hline \multicolumn{4}{|l|}{ Drinking status } \\
\hline Never & $15.8 \pm 6.9$ & $17.0 \pm 8.1$ & 0.015 \\
\hline Ever & $16.0 \pm 7.9$ & $17.1 \pm 8.0$ & 0.264 \\
\hline \multicolumn{4}{|l|}{ Exercise (min/wk) } \\
\hline$<150$ & $16.2 \pm 7.0$ & $18.1 \pm 8.1$ & 0.001 \\
\hline$\geq 150$ & $15.3 \pm 7.2$ & $15.5 \pm 7.7$ & 0.703 \\
\hline \multicolumn{4}{|l|}{ Menopausal status } \\
\hline Premenopause & $15.1 \pm 5.7$ & $17.0 \pm 7.6$ & 0.067 \\
\hline Postmenopause & $15.9 \pm 7.3$ & $17.0 \pm 8.2$ & 0.021 \\
\hline \multicolumn{4}{|l|}{ Body mass index $\left(\mathrm{kg} / \mathrm{m}^{2}\right)$} \\
\hline$<25$ & $15.2 \pm 6.6$ & $17.1 \pm 8.0$ & 0.002 \\
\hline$\geq 25$ & $16.3 \pm 7.6$ & $16.9 \pm 8.1$ & 0.338 \\
\hline \multicolumn{4}{|l|}{ Current job status } \\
\hline Unemployed & $16.3 \pm 7.5$ & $16.8 \pm 8.1$ & 0.390 \\
\hline Employed & $14.9 \pm 6.0$ & $17.2 \pm 7.9$ & 0.001 \\
\hline \multicolumn{4}{|l|}{ Subjective health status } \\
\hline Very healthy, healthy & $12.0 \pm 5.9$ & $13.0 \pm 6.5$ & 0.250 \\
\hline Normal-very unhealthy & $17.3 \pm 7.0$ & $19.2 \pm 8.0$ & 0.001 \\
\hline
\end{tabular}

Values are presented as mean \pm standard deviation. ${ }^{a)}$-value from $t$ test.

The total PWI-SF score was significantly lower in the breast cancer survivor group compared to matched non-cancer controls, suggesting a lower level of psychosocial stress among breast cancer survivors ( $\mathrm{p}=0.006$ ) (Table 2). According to sociodemographic status, total PWI-SF scores were significantly lower among breast cancer survivors than matched non-cancer controls among those whose education level was less than high school level, or college or more, as well as those who: earned $<\$ 3,000 /$ mo of income, were currently married, had never smoked, had never drank, were physically inactive, reported postmenopausal status, had a BMI of $<25 \mathrm{~kg} / \mathrm{m}^{2}$, were currently employed and reported lower subjective health $(\mathrm{p}<0.05)$. In comparison to the non-cancer controls with same characteristics, breast cancer survivors did not show significantly higher levels of stress in any of the sociodemographic characteristics. In addition, according to survival years among breast cancer survivals, there was no significant difference in mean PWI-SF score (2-5 years, 16.5 ; 6 - 10 years, 16.1 ; and $\geq 11$ years, $14.8 ; \mathrm{p}=0.211$; data not shown).

After controlling for the sociodemographic variables, breast cancer survivors were $36 \%$ less likely to have psychosocial stress (odds ratio [OR], 0.64; 95\% confidence interval [CI], 0.42 to 0.98 ), suggesting the lower level of psychosocial stress in breast cancer survivors is an independent effect (Table 3). In addition to cancer survivors status, smok- 
Table 3. Risk factors associated with stress in study population

\begin{tabular}{|c|c|c|}
\hline Variable & Odds ratio $\left.(95 \% \mathrm{CI})^{\mathrm{a}}\right)$ & p-value ${ }^{a}$ \\
\hline \multicolumn{3}{|l|}{ Marital status } \\
\hline Currently unmarried & 1 & \\
\hline Currently married & $0.73(0.50-1.08)$ & 0.112 \\
\hline \multicolumn{3}{|l|}{ Smoking status } \\
\hline Never & 1 & \\
\hline Ever & $2.05(1.01-4.16)$ & 0.046 \\
\hline \multicolumn{3}{|l|}{ Drinking status } \\
\hline Never & 1 & \\
\hline Ever & $1.04(0.74-1.47)$ & 0.820 \\
\hline \multicolumn{3}{|l|}{ Exercise (min/wk) } \\
\hline$<150$ & 1 & \\
\hline$\geq 150$ & $0.64(0.46-0.91)$ & 0.012 \\
\hline \multicolumn{3}{|l|}{ Menopausal status } \\
\hline Premenopause & 1 & \\
\hline Postmenopause & $0.79(0.49-1.29)$ & 0.345 \\
\hline \multicolumn{3}{|l|}{ Body mass index $\left(\mathrm{kg} / \mathrm{m}^{2}\right)$} \\
\hline$<25$ & 1 & \\
\hline$\geq 25$ & $0.89(0.65-1.21)$ & 0.442 \\
\hline \multicolumn{3}{|l|}{ Current job status } \\
\hline Unemployed & 1 & \\
\hline Employed & $1.13(0.80-1.58)$ & 0.498 \\
\hline \multicolumn{3}{|l|}{ Subjective health status } \\
\hline Very healthy, healthy & 1 & \\
\hline Normal-very unhealthy & $4.99(3.11-8.01)$ & $<0.001$ \\
\hline \multicolumn{3}{|l|}{ Group } \\
\hline Breast cancer survivors & $0.64(0.42-0.98)$ & 0.039 \\
\hline Matched non-cancer controls & 1 & \\
\hline
\end{tabular}

CI, confidence interval. a) Results from multivariable conditional logistic regression adjusted for all listed variables.

ing status, habit of exercise, and subjective health status were also independent predictors of psychosocial health (OR, 2.05; 95\% CI, 1.01 to 4.16 for ever smokers; OR, 0.64; 95\% CI, 0.46 to 0.91 for exercise $\geq 150 \mathrm{~min} / \mathrm{wk}$; and OR, $4.99 ; 95 \% \mathrm{CI}, 3.11$ to 8.01 for low subjective health status).

\section{Discussion}

Assessing the QOL in breast cancer survivors has emerged as an important issue given the persisting increase in longterm survivors. We assessed the psychosocial health status, a part of QOL, of breast cancer survivors and matched noncancer controls using baseline data of HEXA cohort. Our findings reveal that breast cancer survivors resuming daily life show significantly better psychosocial health status compared with matched non-cancer controls. In addition, their health behaviors, including alcohol drinking, smoking, physical activity and weight control, are better than non-cancer controls groups. Moreover, these two groups were drawn from the same cohort population and matched by age, education, and income level.

QOL is composed of broad domains that generally include physical, functional, emotional and social well-being. Psychosocial health can be considered as a complex interaction of emotional and social well-being. Emotional well-being is characterized on a range from distress to positive sense of well-being. Social well-being includes social relationships, interactions, and integration. A meta-analysis of QOL in breast cancer survivors showed a mix of positive and negative results [9]. Two studies reported that long-term breast cancer survivors demonstrated an improvement in QOL over time and have a similar QOL to age-matched non-cancer controls in most aspects [22,23]. In one of these studies, outcome for emotional and social well-being of long-term breast cancer survivors were similar to non-cancer controls [22]. A pre- 
vious study conducted by our research team demonstrated that both immediately after a diagnosis of breast cancer and 1 year later, patients reported a lower health-related QOL than the general population [24]. However, study participants were recruited from cancer centers immediately following diagnosis and the follow-up period was only 1 year. Thus participants may not have fully recovered from the impact of breast cancer and treatments, including the side effects, which may explain in part why they reported a lower QOL than the general population.

In the present study, breast cancer survivors showed better psychosocial health status than matched non-cancer controls, and it was consistent across most of the social stratifications analyzed. After adjusting for the effects of sociodemographic factors, breast cancer survivors experienced less stress. We excluded participants less than 2 years from initial diagnosis and those who had not completed treatment, and we randomly selected non-cancer controls matched by age, education attainment level, and household income level. Breast cancer survivors tended drink less alcohol and smoke less and had a better habit of regular exercise compared with matched non-cancer controls. Better health behaviors in cancer survivors have been identified in several previous studies [25-27]. We assumed better health behaviors in breast cancer survivors may be partially attributed to their better psychosocial health status. As the participants in this study voluntarily participate in regular health examinations, they might be considered to be more health conscious than those who don't. The breast cancer survivors with regular health examination had better health behaviors, and this might help explain, why they reported a better psychosocial health status than non-cancer controls. In addition, among these breast cancer survivors, there was not difference between years since breast cancer diagnosis and PWI-SF score, suggesting after recovery, the better psychosocial health of breast cancer survivors would be maintained.

This study is the first to investigate psychosocial health in breast cancer survivors who have resumed daily life by examining community-based data from health examination centers. The difficulties associated with long-term follow-up of breast cancer survivors who have finished adjuvant treatment as well as finding appropriate controls for comparison has limited the study of psychosocial health in long-term cancer survivors because these two groups typically come from different sources. To overcome this hurdle, we assessed the psychosocial health of breast cancer survivors and matched non-cancer controls using baseline data of HEXA cohort, which is assumed to include relatively homogenous populations. Both breast cancer survivors and non-cancer controls from this cohort may be more concerned about their health and more likely to have good health behavior compared to those who don't participate in health checkups [28].

\section{Study limitation}

In our study, some methodological limitations should be mentioned. The study populations included the visitors of health examination centers who get regular health checkups and, thus, they may not represent disease-free breast cancer survivor in Korea and might be more concerned about their health status and maintaining a healthy lifestyle than the general population. Thus, we caution the generalization of our results to all breast cancer survivors. In addition, Berkson's bias which often arise when a study is conducted in a clinic, where attendance was affected by both exposure and disease [29], could affect the study results. A study which applied data from the nationally representative population also presented that there were no differences in stress level between cancer survivors and controls [30]. Although direct comparison of the two results might not be appropriate, our results would be acceptable based on the previous study in Korean population. However, individuals who have survived breast cancer for $\geq 2$ years from initial diagnosis, completed treatment, and received regular medical checkups in health examination centers may represent breast cancer survivors who have fully returned to daily life and could be the target population for management of survivors within a community setting. We defined breast cancer survivors by responses to self-report questionnaires. Although recall bias may have been an issue, previous studies have reported a reasonably high validity for self-report cancer history [31,32], and we considered this information bias to be minimal. Because this study used baseline survey of HEXA cohort, applying observation study, it could be difficult to draw conclusions regarding causal relationships between breast cancer survivor status and psychosocial health level. In addition, although we tried to adjust for all possible confounders measured by questionnaire, there might be residual confounding due to less precise categorization or some confounding variables remain unaccounted for.

\section{Clinical implications}

The present study is the first to report a comparison of psychosocial health between disease-free breast cancer survivors who have resumed daily life and matched non-cancer controls. To increase comparability, breast cancer survivors and non-cancer controls were recruited from the same cohort population, matched by 5-year age groups, education, and household income. In conclusion, breast cancer survivors demonstrated better health behaviors, such as drinking less alcohol, lower BMI, smoking less and exercising more, and revealed better psychosocial health. 


\section{Conflicts of Interest}

Conflict of interest relevant to this article was not reported.

\section{Acknowledgments}

The present study was supported by the grant funded in 2017 by the Korean Foundation for Cancer Research, Seoul, the Republic of Korea. The study was provided with data from the Korean Genome Analysis Project (4845-301), the Korean Genome and Epidemiology (4845-302) and Korea Biobank Project (4851-307, KBP-2014-000), which were supported by the Korean Centers for Disease Control \& Prevention, Republic of Korea.

\section{References}

1. Bray F, Ren JS, Masuyer E, Ferlay J. Global estimates of cancer prevalence for 27 sites in the adult population in 2008. Int J Cancer. 2013;132:1133-45.

2. International Agency for Research on Cancer. Latest world cancer statistics. Global cancer burden rises to 14.1 million new cases in 2012: marked increase in breast cancers must be addressed. Lyon: International Agency for Research on Cancer; 2013

3. Jung KW, Won YJ, Kong HJ, Oh CM, Cho H, Lee DH, et al. Cancer statistics in Korea: incidence, mortality, survival, and prevalence in 2012. Cancer Res Treat. 2015;47:127-41.

4. Howard-Anderson J, Ganz PA, Bower JE, Stanton AL. Quality of life, fertility concerns, and behavioral health outcomes in younger breast cancer survivors: a systematic review. J Natl Cancer Inst. 2012;104:386-405.

5. Bredart A, Kop JL, Fiszer C, Sigal-Zafrani B, Dolbeault S. Breast cancer survivors' perceived medical communication competence and satisfaction with care at the end of treatment. Psychooncology. 2015;24:1670-8.

6. Gallicchio L, Kalesan B, Hoffman SC, Helzlsouer KJ. Non-cancer adverse health conditions and perceived health and function among cancer survivors participating in a communitybased cohort study in Washington County, Maryland. J Cancer Surviv. 2008;2:12-9.

7. Agrawal S. Late effects of cancer treatment in breast cancer survivors. South Asian J Cancer. 2014;3:112-5.

8. Eakin EG, Youlden DR, Baade PD, Lawler SP, Reeves MM, Heyworth JS, et al. Health status of long-term cancer survivors: results from an Australian population-based sample. Cancer Epidemiol Biomarkers Prev. 2006;15:1969-76.

9. Chopra I, Kamal KM. A systematic review of quality of life instruments in long-term breast cancer survivors. Health Qual Life Outcomes. 2012;10:14.

10. Perry S, Kowalski TL, Chang CH. Quality of life assessment in women with breast cancer: benefits, acceptability and utilization. Health Qual Life Outcomes. 2007;5:24.

11. Bloom JR, Petersen DM, Kang SH. Multi-dimensional quality of life among long-term (5+ years) adult cancer survivors. Psychooncology. 2007;16:691-706.
12. Stagl JM, Bouchard LC, Lechner SC, Blomberg BB, Gudenkauf LM, Jutagir DR, et al. Long-term psychological benefits of cognitive-behavioral stress management for women with breast cancer: 11-year follow-up of a randomized controlled trial. Cancer. 2015;121:1873-81.

13. Mols F, Vingerhoets AJ, Coebergh JW, van de Poll-Franse LV. Quality of life among long-term breast cancer survivors: a systematic review. Eur J Cancer. 2005;41:2613-9.

14. Burgess C, Cornelius V, Love S, Graham J, Richards M, Ramirez A. Depression and anxiety in women with early breast cancer: five year observational cohort study. BMJ. 2005;330:702.

15. Massie MJ. Prevalence of depression in patients with cancer. J Natl Cancer Inst Monogr. 2004:57-71.

16. Health Examinees Study Group. The Health Examinees (HEXA) study: rationale, study design and baseline characteristics. Asian Pac J Cancer Prev. 2015;16:1591-7.

17. Chang S. Standardization of collection and measurement of health statistics data. Seoul: Korean Society for Preventive Medicine; 2000. p. 111-35.

18. Chang WH, Sohn MK, Lee J, Kim DY, Lee SG, Shin YI, et al. Korean Stroke Cohort for functioning and rehabilitation (KOSCO): study rationale and protocol of a multi-centre prospective cohort study. BMC Neurol. 2015;15:42.

19. Koh DH, Han SS, Kim HR, Chang SJ, Choi SH, Won JU, et al. Analysis of the role of social support on job stress and psychosocial stress in automobile factory workers using Structural Equation Model. Korean J Occup Environ Med. 2005;17:79-84.

20. Lim DK, Baek KO, Chung IS, Lee MY. Factors related to sleep disorders among male firefighters. Ann Occup Environ Med. 2014;26:11.

21. Rock CL, Doyle C, Demark-Wahnefried W, Meyerhardt J, Courneya KS, Schwartz AL, et al. Nutrition and physical activity guidelines for cancer survivors. CA Cancer J Clin. 2012;62:243-74.

22. Hsu T, Ennis M, Hood N, Graham M, Goodwin PJ. Quality of life in long-term breast cancer survivors. J Clin Oncol. 2013;31: 3540-8.

23. Koch L, Jansen L, Herrmann A, Stegmaier C, Holleczek B, 
Singer S, et al. Quality of life in long-term breast cancer survivors: a 10-year longitudinal population-based study. Acta Oncol. 2013;52:1119-28.

24. Lee ES, Lee MK, Kim SH, Ro JS, Kang HS, Kim SW, et al. Health-related quality of life in survivors with breast cancer 1 year after diagnosis compared with the general population: a prospective cohort study. Ann Surg. 2011;253:101-8.

25. Hawkes AL, Pakenham KI, Chambers SK, Patrao TA, Courneya KS. Effects of a multiple health behavior change intervention for colorectal cancer survivors on psychosocial outcomes and quality of life: a randomized controlled trial. Ann Behav Med. 2014;48:359-70.

26. Kye SY, Park K. Psychosocial factors and health behavior among Korean adults: a cross-sectional study. Asian Pac J Cancer Prev. 2012;13:49-56.

27. Blanchard CM, Courneya KS, Stein K; American Cancer Society's SCS-II. Cancer survivors' adherence to lifestyle behavior recommendations and associations with health-related quality of life: results from the American Cancer Society's SCS-II. J
Clin Oncol. 2008;26:2198-204.

28. Hoebel J, Starker A, Jordan S, Richter M, Lampert T. Determinants of health check attendance in adults: findings from the cross-sectional German Health Update (GEDA) study. BMC Public Health. 2014;14:913.

29. Westreich D. Berkson's bias, selection bias, and missing data. Epidemiology. 2012;23:159-64.

30. Choi KH, Park SM. Psychological status and associated factors among Korean cancer survivors: a cross-sectional analysis of the fourth \& fifth Korea National Health and Nutrition Examination Surveys. J Korean Med Sci. 2016;31:1105-13.

31. Cho LY, Kim CS, Li L, Yang JJ, Park B, Shin A, et al. Validation of self-reported cancer incidence at follow-up in a prospective cohort study. Ann Epidemiol. 2009;19:644-6.

32. Bergmann MM, Calle EE, Mervis CA, Miracle-McMahill HL, Thun MJ, Heath CW. Validity of self-reported cancers in a prospective cohort study in comparison with data from state cancer registries. Am J Epidemiol. 1998;147:556-62. 